\title{
Unintended consequences of COVID-19: Opportunities for respiratory therapists' involvement in developing respiratory-related technologies
}

\author{
Patricia McClurg RRT, MEd ${ }^{1}$, Nikolay Moroz RRT, MD², Marco Zaccagnini, RRT/CCAA, FCSRT, MSc ${ }^{2,3}$
}

\begin{abstract}
P McClurg, N Moroz, M Zaccagnini. Unintended consequences of COVID-19: Opportunities for respiratory therapists' involvement in developing respiratory-related technologies. Can J Respir Ther 2020;56:35-37. doi: 10.29390/cjrt-2020-032.
\end{abstract}

Key Words: respiratory therapy; technology; pandemics; coronavirus infections; mechanical ventilators.

\section{INTRODUCTION}

More than ever, the role of the registered respiratory therapist (RRT) is critical to Canadians' health. Nationally, RRTs are mobilizing their efforts to battle a novel viral enemy. Members of the Canadian RRT community, from clinicians to educators to students, are meeting the challenge of the COVID-19 pandemic crisis. RRTs have consistently demonstrated innovation, professionalism, and a commitment to providing evidence-based care for patients through the profession's 50-year history; this remains unchanged and arguably more apparent considering the COVID-19 pandemic. RRTs' clinical experience, expertise, and academic training render RRTs indispensable in some unintended consequences of the COVID-19 pandemic. One of these unintended consequences of the COVID-19 pandemic is the rapid development of innovative respiratory-related technologies.

\section{The need to develop new respiratory technology}

A significant consequence of the COVID-19 pandemic is the shortage of medical equipment (e.g., personal protection equipment [1]). On 20 March 2020, the Government of Canada asked Canadian businesses and industrialists to help develop and manufacture supplementary health care supplies for health professionals [2]. Since the call, almost 3,000 companies have volunteered their engineering and manufacturing expertise, including their facilities, to produce medical equipment. Some include clothing brands repurposing stock to provide medical gowns and sports manufacturers providing face shields [3, 4]. Comparisons of this type of industry collaboration have been made to automobile companies' wartime efforts-including Ford and GM-to produce tanks and airplanes using their factories during World War II [5]. RRTs working directly with patients with COVID-19 have the firsthand experience and knowledge to be invaluable counsel for these companies on medical equipment requirements.

Another significant consequence of the pandemic includes a potential shortage of available critical care mechanical ventilators [6]. The Canadian government acknowledged the potential shortage and focused its efforts to secure and manufacture Canadian-made mechanical ventilators. Additionally, the Canadian-made mechanical ventilators would be distributed to other countries if not required in Canada [7]. The call for Canadian-made mechanical ventilators mobilized many medical experts and entrepreneurs to design and produce easy-to-use mechanical ventilators rapidly. Collaboration across the world has already resulted in many ventilator prototypes and adjunct therapy devices. Some were designed by large established medical companies [8], while some made by small, independent teams [9]. These devices need to be built quickly and inexpensively with readily available hardware and infrastructure. The devices must be user-friendly so that all health care professionals are easily able to learn to use them while still ensuring minimal safety standards.

\section{The unique role of RRTs in developing new} respiratory technologies

A considerable challenge for manufacturers not in health care is to engineer and build a device without the required expertise. Crucial to these projects' success is the input and guidance from clinicians who have an extensive understanding of respiratory therapy equipment and its usage in clinical practice. RRTs are the professionals whose education focuses on the knowledge and application of various modalities of oxygen therapy and mechanical ventilation, which are prominent in the battle against COVID-19. As a result, RRTs across the country are participating in multiple ventures-from designing and testing new ventilator prototypes to developing alternate respiratory care options to treat patients diagnosed with COVID-19. To illustrate how RRTs contribute to the development of new respiratory technologies, we briefly describe some roles we have assumed during the current health care crisis.

1) Providing laboratory space and equipment to test mechanical ventilator prototypes. Manufacturers developing prototypes must rigorously test these devices to meet safety standards before production can begin. During this pandemic, many RRTs in hospital, community, and educational institutions have provided testing items such as oxygen analyzers, test lungs, spirometers, circuits, and adaptors to various companies who have created prototypes [10]. RRTs are vital gatekeepers to many essential items and locations for testing.

2) Supporting mechanical, computer, and software engineers in the design and ergonomics of their prototype ventilator. As companies responded to the call from the Canadian government, ventilator

\footnotetext{
${ }^{1}$ Respiratory and Anesthesia Technology, Vanier College, Montréal, Québec

${ }^{2}$ Department of Respiratory Therapy, McGill University Health Centre, Montréal, Québec

${ }^{3}$ School of Physical and Occupational Therapy, McGill University, Montréal, Québec

Correspondence: Nikolay Moroz, Department of Respiratory Therapy, McGill University Health Centre, Montréal, Québec, 1001 Decarie Blvd, Montreal, QC H4A 3J1, Canada, E-mail: nikolay.moroz@muhc.mcgill.ca
}

Published online at https://www.cjrt.ca on 10 September 2020 
designs needed verification before manufacturing and, ultimately, testing of a prototype could take place. Essential in the design meetings was the presence of someone with expertise in mechanical ventilation. For the most part, the only medical equipment expert among the physicists and engineers attending these meetings was the RRT. This early association with the RRT helped to minimize the time from design to testing a prototype mechanical ventilator capable of providing ventilatory support for patients with respiratory failure caused by COVID-19

3) Collaborating with international groups on the basic design of a prototype ventilator. The expertise of individuals with an extensive background in mechanical ventilation was required to collaborate with international groups on the design, documentation, and production of a usability report to obtain Health Canada Interim approval of a mechanical ventilator. One such group is the "Mechanical Ventilator Milano" [11] which was the result of a cooperative effort of particle and nuclear physicists and physicians from Canada (Queen's University), Italy, the United States (Princeton University), France, and Spain to collaborate in designing a mechanical ventilator.

4) Assisting with the creation and editing of the ventilator prototype's operating manual. As mentioned above, any technology created requires thorough and detailed documentation for safety and usability purposes.

5) Serving on a committee evaluating ventilator prototypes as part of a challenge for engineers to submit a proposal for building a suitable pandemic ventilator. This challenge was a joint initiative between The Montreal General Hospital Foundation and the Research Institute of the McGill University Health Centre. It called for teams of engineers and scientists from anywhere in the world to design a simple, low-cost, easy to manufacture, and easy to maintain ventilator that could be deployed anywhere. Nine semifinalists were chosen for the final round by providing a verifiable ventilator and meeting the design requirements. The judges included an intensivist, a ventilator manufacturer, and an RRT. Again, the knowledge of an RRT was sought out and considered essential for this judging panel [9].

6) Collaborating with clinicians and researchers on a noninvasive continuous positive airway pressure (CPAP) mask alternative to be used when mechanical ventilation may not be available and/or is not indicated. The project entails documenting and finding solutions for repurposing available models of snorkeling masks as interfaces for noninvasive CPAP delivery. These devices could provide a therapeutic option between standard oxygen delivery devices (e.g., low-flow nasal cannulas, venturi masks, nonrebreather masks, highflow nasal cannulas) and limited resources for invasive ventilation [12]. This project aims to openly share collaborative documentation and innovation for repurposing equipment to provide novel solutions to respiratory equipment. RRTs were sought out as experts in oxygen therapy equipment.

7) Providing educational assistance regarding ventilatory management and oxygen therapy practice guidelines on social media platforms as free, open-access medicine [13]. The RRT's role has been integral in the management and treatment of COVID-19 because the disease targets the respiratory system. RRTs' clinical and academic experience allows them to share and critique COVID-19. related empirical literature online with Canadian, North American, and international clinicians in the medical community [14-16].

8) Advising public health agencies regarding the procurement of pandemic mechanical ventilators. Providing rapid reviews and evidence-based recommendations for pandemic-specific mechanical ventilators [17].

RRTs are professionals who possess a thorough understanding of the technology required in critical and respiratory care medicine. RRTs are playing a pivotal role during the COVID-19 pandemic. In addition to the relentless bedside care, RRTs are undertaking new initiatives caused by the pandemic. The preceding commentary outlines some initiatives that the authors have contributed their knowledge and expertise. However, we are not unique in this regard. Based on anecdotal conversations between colleagues across Canada, many RRTs are involved in novel initiatives. It is vital to come forth and showcase the efforts and innovation of Canadian RRTs who serve as important liaisons between technical and clinical members of research and development teams and should continue these collaborations post-pandemic. RRTs have demonstrated their importance in the medical, research, and innovation teams and should continue forging novel paths to further develop the RRT profession.

\section{ACKNOWLEDGEMENTS}

We would like to thank Costa Voutsinas, RRT, for his input when drafting this commentary.

\section{REFERENCES}

1. Canadian Society of Respiratory Therapists. RTs preparing for the capacity challenges posed by COVID-19. 2020. Available at: https://www.csrt. $\mathrm{com} / 2020 / 04 /$ rts-preparing-for-the-capacity-challenges-posed-bycovid-19/ (Accessed July 4, 2020)

2. Justin Trudeau PMoC. Partnerships with Canadian industry to fight the COVID-19 pandemic. 2020. Available at: https://pm.gc.ca/en/news/ backgrounders/2020/03/31/partnerships-canadian-industry-fight-covid19-pandemic (Accessed July 4, 2020)

3. Canada Goose Holdings Inc. Canada Goose Response Program Update: COVID-19. 2020. Available at: https://investor.canadagoose.com/ English/news-results-and-presentations/press-release/press-releasedetails/2020/Canada-Goose-Response-Program-Update-COVID-19/ default.aspx (Accessed July 4, 2020)

4. Global News. 'Team first': Bauer Hockey making face shields for coronavirus fight. 2020. Available at: https://globalnews.ca/news/6734828/ coronavirus-bauer-face-shields/ (Accessed July 4, 2020)

5. Vox Media. Ford and GM are making tens of thousands of ventilators. It may already be too late. 2020. Available at: https://www.vox.com/ recode/2020/4/10/21209709/tesla-gm-ford-ventilators-coronavirus (Accessed July 4, 2020)

6. American Association for Respiratory Care. Ventilators are key to preventing coronavirus deaths-but does the world have enough of them? 2020. Available at: https://www.aarc.org/wp-content/ uploads/2020/03/Ventilators-prevent-coronavirus-deaths-Fortune.pdf (Accessed July 4, 2020)

7. Nardi C. Canadian firms will produce 30,000 new ventilators as officials prepare for COVID-19 worst-case scenario. National Post2020. Available at: https://nationalpost.com/news/canadian-firms-will-produce-30000new-ventilators-as-officials-prepare-for-worst-case-covid-19-scenario (Accessed July 4, 2020)

8. Global News. CAE ventilator receives Health Canada certification, starts shipping. 2020. Available at: https://globalnews.ca/news/7077957/ cae-ventilators-canada-coronavirus/ (Accessed July 4, 2020)

9. The Montreal General Hospital Foundation. Code Life Ventilator Challenge. 2020. Available at: https://www.mghfoundation.com/en/ news/code-life-ventilator-challenge/ (Accessed July 4, 2020)

10. Vanier College. Vanier pandemic heroines and heroes. 2020. Available at: https://www.vaniercollege.qc.ca/newsroom/vanier-pandemic-heroines-and-heroes/ (Accessed July 4, 2020)

11. Fuller-Wright L. Particle physicists design simplified ventilator for COVID-19 patients. Office of Communications, Princeton University; 2020. Available at: https://www.princeton.edu/news/2020/04/09/ particle-physicists-design-simplified-ventilator-covid-19-patients (Accessed July 4, 2020)

12. ScubPAP Documentation Project. ScubPAP Documentation Project. 2020. Available at: https://docs.google.com/document/d/1lIxzLe9wkgt4wh4kcznvBKmciGSwYmCgXIALS6mYUlI/edit?ts=5e8e0332\#heading $=h$.fctnyfkfwr 3 (Accessed July 4, 2020)

13. Wong A, Jonathan W, Malbrain M. Free Open Access Medical education (FOAM): the new way to keep up-to-date. 2020. Available at: https://blogs.biomedcentral.com/on-medicine/2018/06/08/freeopen-access-medical-education-foamed-new-way-keep-date/ (Accessed July 4, 2020)

14. Piraino T. Facebook page., 2020. Available at: https://www.facebook. $\mathrm{com} /$ respresource (Accessed July 4, 2020)

15. The Toronto Centre of Excellence in Mechanical Ventilation. A message to respiratory therapists and bedside clinicians regarding COVID-19 Management. 2020. Available at: https://coemv. 
ca/a-message-to-respiratory-therapists-and-bedside-clinicians-regardingcovid-19-management/ (Accessed July 4, 2020)

16. Canadian Society of Respiratory Therapists. CSRT Rapid Response Refresher Toolkit. 2020. Available at: https://www.csrt.com/csrt-rapidresponse-refresher-toolkit/ (Accessed July 4, 2020)
17. Canadian Society of Respiratory Therapists. National Emergency Strategic Stockpile - Mechanical Ventilators Resources for Respiratory Therapists. 2020. Available at: https://www.csrt.com/wp-content/ uploads/strategic-stockpile-resources-by-ventilator.pdf (Accessed July 4, 2020) 